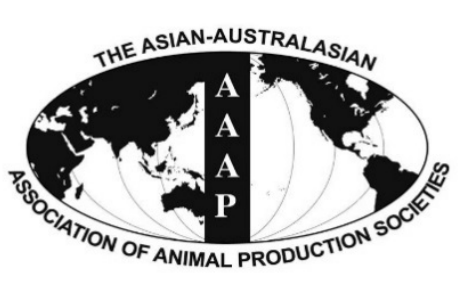

Open Access

Asian Australas. J. Anim. Sci.

Vol. 29, No. 3 : 428-435 March 2016

http://dx.doi.org/10.5713/ajas.15.0190

www.ajas.info

pISSN 1011-2367 elSSN 1976-5517

\title{
The Effects of Components of Grazing System on Welfare of Fattening Pigs
}

\author{
Akitsu Tozawa, Shigefumi Tanaka, and Shusuke Sato* \\ Graduate School of Agricultural Science, Tohoku University, Miyagi 989-6711, Japan
}

\begin{abstract}
The objective of this study was to clarify the most effective component of grazing for improving welfare of fattening pigs. This study compared welfare indicators of 20 fattening pigs aged 100 to 124 days (the prior period) and 138 to 164 days (the latter period) in an indoor housing system (IS), an outdoor pasturing system (OP), a concrete floor paddock system (CF), a concrete floor paddock system with fresh grass (FG), or a soil floor paddock system (SF). The last three treatments include important components of a grazing system: extra space, grass feed, and soil floor. Behavior, wounds on the body, and performances, measured as average daily gain (ADG) and feed conversion ratio, were observed. CF pigs behaved similarly to IS pigs. FG pigs showed higher levels of foraging, chewing and activity. SF pigs engaged in higher levels of foraging, exploring, activity, and rooting, and showed a similar amount of playing behavior as OP pigs. ADG was the same in all treatments at the prior period, and increased in the order FG, IS, CF, SF, and OP at the latter. The behaviors and performance of SF pigs resembled those of OP which seemed to indicate a consistently higher standard of welfare than the other treatments. In conclusion, the existence of a soil floor is the most important component of a pasture for improving the welfare of pigs. (Key Words: Behavior, Grass, Grazing, Pigs, Soil, Space Allowance)
\end{abstract}

\section{INTRODUCTION}

The welfare of animals is known to be reduced in intensive production systems with small space allowances and barren environments. Investigations in the past have focussed specifically on the importance of space allowance for farmed animals (Petherick, 1983). Physical restrictions cause psychological stress for animals (Baxter, 1984), resulting in the expression of aberrant behaviors and aggression. An environment in an intensive production system may restrict the expression of species-specific behavior and may lead to chronic stress in animals (Pearce and Paterson, 1993; Beattie et al., 1995).

Exploring the environment by rooting with their snouts is one of the strongest intrinsic behaviors in pigs (Beattie and O'Connell, 2002). The absence of suitable objects as rooting materials may induce redirection of rooting behavior to other materials such as pen fixtures (Beattie et al., 1995; Guy et al., 2002) and pen mates (Beattie et al.,

\footnotetext{
* Corresponding Author: Shusuke Sato. Tel: +81-229-84-7376, Fax: +81-229-84-7382, E-mail: shusato@bios.tohoku.ac.jp Submitted Mar. 4, 2015; Revised May 8, 2015; Accepted Jun. 8, 2015
}

1995; de Jong et al., 1998), which leads to behavioral problems such as tail-biting and aggression (Beattie et al., 1995; Petersen et al., 1995).

In an outdoor pasturing system, pigs are offered a large space allowance and an enriched environment. Many studies have indicated that rearing pigs at pasture improves their welfare (Stolba and Wood-Gush, 1989), but we do not know which specific components of the grazing system lead to this benefit.

Some studies have shown that providing enrichment materials in barren environments improves welfare and reduces stress (Beattie et al., 1995; Petersen et al., 1995; Day et al, 2002). Enrichment materials that are rootable, destructible, and edible are recommended for pigs to manipulate (Bracke et al., 2006). Materials such as straw (Fraser et al., 1991), peat (Beattie et al., 1998), and earth (Wood-Gush and Beilharz, 1983; Appleby and Wood-Gush, 1988) can meet these requirements.

The objective of this study was to clarify the effects of extra space, grass feed and a soil floor as components of the grazing system on welfare of fattening pigs. To clarify the effects of these factors, we first compared welfare indicators of fattening pigs in an indoor housing system (IS) 
and an outdoor pasturing system (OP), and then compared welfare indicators between systems comprising a concrete floor paddock (CF), a concrete floor paddock with fresh grass (FG), and a soil floor paddock (SF).

\section{MATERIAL AND METHODS}

\section{Design}

This study was carried out at the Field Science Center, the Graduate School of Agricultural Science, Tohoku University in Japan (latitude $38^{\circ} 45^{\prime}$, longtitude $140^{\circ} 45^{\prime}$, altitude $215 \mathrm{~m}$ ). Pigs were reared from the end of June to mid-October and sampling was divided into the prior period, starting in mid-July (from 45.3 to $61.7 \mathrm{~kg}, 100$ to 124 days of age), and the latter period, starting in mid-August (from 72.1 to $91.4 \mathrm{~kg}, 138$ to 164 days of age). All pigs were transported to a slaughterhouse in mid-October at 193 days old.

Five treatments were established on the same pasture. Behaviors, wounds on the body, and performance were used as indicators of pig welfare.

\section{Housing}

An open-air, roofed pen, measured $1.8 \times 2.7 \mathrm{~m}$, was constructed for each treatment (Figure 1a). Two side of the pen were covered with $0.9-\mathrm{m}$-high solid panels, and the other was covered with a gridiron panel and a gridiron door of the same height. Half of the floor in the pen was made of plastic-coated woven wire and the other half was solid as wood. The floor of the pen was a raised deck to drain away excrements in the IS treatment, but others were only just placed in the paddock. A four-partitioned feeder and a water cup were placed inside the pen for the IS treatment and outside near the pen for the other treatments, respectively. The OP, CF, FG and SF treatments were offered a paddock measuring $10 \times 20 \mathrm{~m}$, which was surrounded by an electric fence. Each paddock consisted of pasture in OP, a concrete floor in $\mathrm{CF}$ and FG, and a soil floor in SF. All pigs in OP, $\mathrm{CF}, \mathrm{FG}$, and SF could freely access the pen and the outside paddock (Figure 1b). Two grassland paddocks were prepared for the prior and the latter periods in the OP treatment. The dominant species in the pasture were Kentuckey bluegrass (Poa pratensis), Italian ryegrass (Lolitum multiflorum) and Redtop (Agrostis alba). In the prior period, grasses were in the harvest stage and the herbage mass was 200 to $400 \mathrm{~g} / \mathrm{m}^{2}$ dry matter. Grasses were cut 20 days before the start of the latter period.

Pigs in the IS and OP treatments were reared in the same paddocks throughout both the prior and the latter periods as controls for $\mathrm{CF}, \mathrm{FG}$, and SF treatments. Pigs reared in the $\mathrm{CF}, \mathrm{FG}$, and $\mathrm{SF}$ treatments for the prior period were switched to the FG, SF, and CF treatments, respectively, on the final day of the prior period. Pigs were acclimatized to the environments until the beginning of the latter period. Considering effects of behavior against other pigs in the group, we didn't change the members of each group.

The $\mathrm{CF}$ and the FG treatments were adjacent to each other and were separated by an electric fence. The SF treatment was $10 \mathrm{~m}$ apart from the FG treatment, and the IS treatment was $10 \mathrm{~m}$ apart from the SF treatment, on the opposite side of the FG treatment. The OP treatment was adjacent to the IS treatment, approximately $10 \mathrm{~m}$ away.

\section{Animals and management}

Twenty specific pathogen-free, castrated male pigs (Landrace $\times$ Large White) were used in this study. These pigs were derived from five litters from the same farm. One pig from each litter was allocated to each treatment. Pigs were divided in five treatments of four pigs each.

Pigs in the five treatments were fed the same concentrate for the entire period. The ingredients and composition of the diet are presented in Table 1. Feed and water were available ad libitum. In addition to the

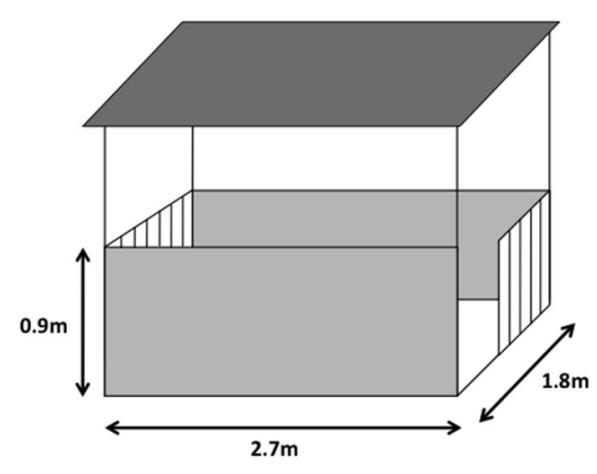

(a) An open-air roofed pen containing a drinker and a feeder

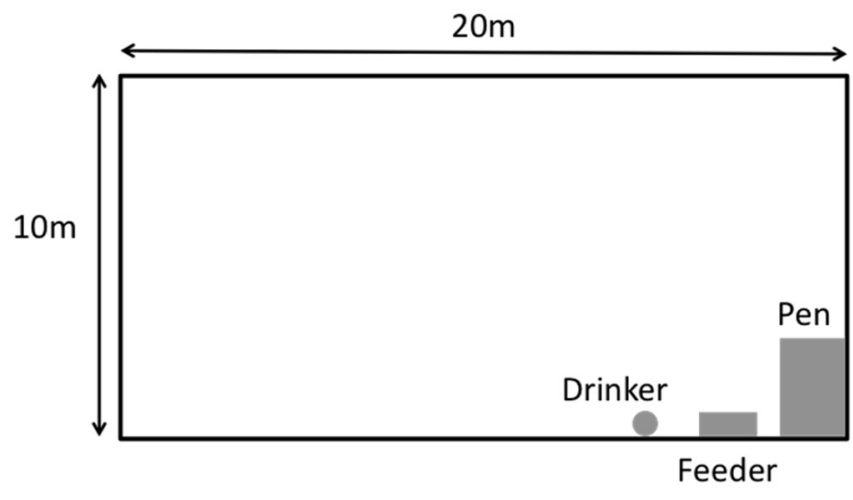

(b) A layout of a pen and a paddock in $\mathrm{OP}, \mathrm{CF}, \mathrm{FG}$ and SF treatments

Figure 1. Schematic diagram of an open-air roofed pen and a paddock. 
Table 1. Ingredient and composition of the diet (as-fed basis, \%)

\begin{tabular}{lc}
\hline Items & \\
\hline Ingredient & 67 \\
Corn, grain sorghum & 24 \\
Soybean oil cake, rapeseed oil cake & 3 \\
Distillers dried grains with solubles & 1 \\
Fish meal & 5 \\
Others & \\
$\quad$ Animal oil and fat, $\mathrm{CaOH}_{2}, \mathrm{HCl}, \mathrm{Critic}$ acid & \\
$\quad$ Acidum tartaricum, $\mathrm{Malic}$ acid, Silicic acid & \\
Composition & $\geq 16.0$ \\
Crude protein & $\geq 4.0$ \\
Crude fat & $\leq 5.0$ \\
Crude fiber & $\leq 7.0$ \\
Crude ash & $\geq 0.5$ \\
Ca & $\geq 0.4$ \\
$\mathrm{P}$ & $\geq 80.0$ \\
Total digestible nutrients & \\
\hline
\end{tabular}

concentrate, FG pigs were fed $2 \mathrm{~kg}$ of fresh grasses every morning. Excreta were removed every morning to maintain good hygiene in each treatment.

Pigs were aged 87 days and weighed (mean \pm SD) $33.9 \pm 2.1 \mathrm{~kg}$ on average when introduced from a commercial farm to the university farm and divided into groups. The average weights of pigs in each treatment were $\mathrm{IS}=46.5 \pm 3.3 \mathrm{~kg}, \mathrm{OP}=43.3 \pm 1.2 \mathrm{~kg}, \mathrm{CF}=45.9 \pm 2.0 \mathrm{~kg}, \mathrm{FG}$ $=46.3 \pm 1.9 \mathrm{~kg}, \mathrm{SF}=44.8 \pm 1.3 \mathrm{~kg}$ at the start of the prior period. At the start of the latter period, pigs weighed IS = $78.1 \pm 1.8 \mathrm{~kg}, \mathrm{OP}=70.1 \pm 1.4 \mathrm{~kg}, \mathrm{CF}=69.4 \pm 3.3 \mathrm{~kg}, \mathrm{FG}=$ $76.6 \pm 2.1 \mathrm{~kg}, \mathrm{SF}=66.3 \pm 3.5 \mathrm{~kg}$. They were slaughtered at 193 days old, weighed $115.6 \pm 8.2 \mathrm{~kg}$ on average.

\section{Behavioral observations}

Behavioral observations were conducted more than 13 days after the start of the two experimental periods. Pigs in the prior and the latter periods were observed at 16 and 21 weeks of age, respectively.

Behavioral sampling was performed by scan and onezero sampling (Martin and Bateson, 1986). Both methods were used for $7 \mathrm{~h}$ between 06.00 and $10.00 \mathrm{~h}$ and between 15.00 and $18.00 \mathrm{~h}$ for 2 days each, corresponding with times when pigs were active. These samplings were directly observed by a particular person. Pigs were marked on each back in order to recognized individuals.

Behavioral states: Behavioral states (Martin and Bateson, 1986) were monitored 168 times by instantaneous sampling at 5-min intervals for each pig. The ethogram for these observations is shown in Table 2.

Event behaviors: Disturbed behaviors, playing, chewing, rooting, and social behaviors were monitored as events by one-zero sampling (Martin and Bateson, 1986). As durations were shorter than 5-min and frequencies were generally once per $30 \mathrm{~s}$, one-zero sampling was considered reasonable for these behavioral categories.

Event behaviors of all pigs in one treatment were observed every $30 \mathrm{~s}$ for 4-min periods continuously giving, eight observations per session. After the 4-min observation period, the observer moved to the next treatment within one minute and performed the behavior sampling in the same way. One observation cycle consumed 25-min (5 treatments $\times 5 \mathrm{~min}$ ) and was repeated after 5 -min rest for $7 \mathrm{~h}$ per day on 2 days. There was a maximum value of 224 onezero samples per pig in each behavioral category.

\section{Wounds on the body}

Wounds on pigs' body were assessed using the Welfare Quality assessment protocol (Welfare Quality Consortium, 2009) on the day of transport or the day before. Each pig's body was divided into five parts: ears, front (head to back of

Table 2. Ethogram of pig state and event behaviors

\begin{tabular}{ll}
\hline Behavior & \\
\hline Behavior as a state & Total time of feeding, grass eating and soil eating \\
Foraging & Gathering, chewing and swallowing concentrates \\
Feeding & Gathering, chewing and swallowing fresh grasses \\
Grass eating & Chewing and swallowing soil \\
Soil eating & Sniffing surrounding environment, rooting and chewing rocks \\
Exploring & Animal is not performing any activity \\
Resting & The focal animal is not involved in any of the listed behaviors \\
Others & Chewing or rooting pen mates, chewing or biting facilities and sham-chewing (re-directed behavior, \\
Behavior as an event & displacement behavior, vaccum behavior) \\
Disturbed behavior & Chasing, jumping, and head-knocking with pen mates \\
& Chewing action with objects (grass, soil, or food) in the pig's mouth \\
Playing & Back-and-forth movement of the snout over soil, but not a pen mate \\
Chewing & Head-butting or aggressive biting at a pen mate \\
Rooting & Smelling or licking a pen mate \\
Agonistic behavior & \\
Affiliative behavior &
\end{tabular}


shoulder), middle (back of shoulder to hindquarters), hindquarters, and legs (from the accessory digit upwards). All pigs were checked on both sides of the body, and the points from both sides were totalled.

\section{Performances}

The weight of each pig was recorded during the prior and the latter periods to calculate the average daily gain (ADG). Pigs were slaughtered at 193 days of age when they weighed $115.6 \pm 8.2 \mathrm{~kg}$ on average.

Feed conversion ratio (FCR) per pen was also calculated in the prior and the latter periods. The amounts of concentrate fed and removed were weighed every day, and FCR was calculated in each treatment at the end of the period.

\section{Statistical analysis}

The individual data for each pig in each treatment for behavior, wounds on the body, and the gain to feed ratio were tested the normality by Shapiro-Wilk test and subjected to general linear model analyses of variance using the statistical package $\mathrm{R}$ ver. 3.0.2 (R Development Core Team, 2013). The model used for the final analysis was :

$$
\mathrm{Y}_{i}=\mu+\mathrm{T}_{i}+\mathrm{E}_{i}
$$

where $Y_{i}$ is the dependent variable, $\mu$ is the overall mean, $\mathrm{T}_{i}$ is the treatment effect and $\mathrm{E}_{i}$ is the residual error.
When the treatment effect was significant $(p<0.05)$, differences were compared using the Tukey honestly significant difference test. The student's $t$-test was used to compare behaviours between the prior and the latter periods. The Student's $t$-test was also used to compare the time spent eating grass in the OP and FG treatments and the time spent eating soil in the OP and SF treatments.

Less than $0.05 \mathrm{p}$ values were considered a significant, and those less than 0.10 were considered as a tendency.

\section{RESULTS}

\section{Comparison between IS and OP pigs}

Behavioral states: Table 3 shows the time budgets of seven behavioral categories as a state in the prior and the latter periods. There were apparent differences between IS and OP pigs in grass eating and soil eating, which occurred only in OP. There were no differences in other behaviors between IS and OP pigs in the prior period. In the latter period, there were several differences between IS and OP pigs. OP pigs expressed more foraging and exploratory behavior and less resting than IS pigs $(\mathrm{p}<0.05)$. Comparison of the two periods showed that the time spent foraging and feeding in IS pigs significantly decreased $(\mathrm{p}<0.05)$, resting time significantly increased $(\mathrm{p}<0.05)$, and the time spent exploring tended to decrease $(\mathrm{p}<0.1)$ from the prior to the latter periods. There was no significant change in the time spent on any behavior in OP pigs, regardless of advancing

Table 3. Time budgets ( $\%$ in the observation period) of behavioral states in pigs in the five treatments

\begin{tabular}{|c|c|c|c|c|c|c|}
\hline \multirow{2}{*}{ Behavior } & \multicolumn{5}{|c|}{ Treatment } & \multirow{2}{*}{ p-value } \\
\hline & IS & $\mathrm{OP}$ & $\mathrm{CF}$ & FG & $\mathrm{SF}$ & \\
\hline \multicolumn{7}{|l|}{ Prior period } \\
\hline Foraging & $18.2 \pm 2.6^{\mathrm{c}}$ & $20.1 \pm 3.3^{\mathrm{bc}}$ & $16.5 \pm 2.1^{\mathrm{c}}$ & $34.5 \pm 3.9^{\mathrm{a}}$ & $27.2 \pm 4.8^{\mathrm{ab}}$ & $<0.001$ \\
\hline Feeding & $18.2 \pm 2.6$ & $12.8 \pm 3.7$ & $16.5 \pm 2.1$ & $18.0 \pm 4.3$ & $19.9 \pm 3.8$ & 0.085 \\
\hline Grass eating & - & $4.5 \pm 2.0^{\mathrm{b}}$ & - & $16.5 \pm 3.1^{\mathrm{a}}$ & - & $0.001^{1}$ \\
\hline Soil eating & - & $2.8 \pm 1.3^{b}$ & - & - & $7.3 \pm 1.1^{\mathrm{a}}$ & $0.002^{1}$ \\
\hline Exploring & $6.1 \pm 2.3^{b}$ & $11.5 \pm 5.2^{\mathrm{b}}$ & $15.5 \pm 5.6^{\mathrm{ab}}$ & $12.1 \pm 6.6^{\mathrm{b}}$ & $23.4 \pm 3.2^{\mathrm{a}}$ & 0.002 \\
\hline Resting & $65.5 \pm 4.3^{\mathrm{c}}$ & $60.4 \pm 2.0^{c}$ & $55.8 \pm 7.8^{\mathrm{bc}}$ & $45.8 \pm 3.8^{\mathrm{ab}}$ & $33.8 \pm 8.9^{\mathrm{a}}$ & $<0.001$ \\
\hline Others & $10.3 \pm 3.7$ & $8.0 \pm 1.9$ & $12.2 \pm 3.0$ & $7.6 \pm 1.8$ & $15.6 \pm 2.8$ & - \\
\hline \multicolumn{7}{|l|}{ Latter period } \\
\hline Foraging & $12.7 \pm 1.0^{\mathrm{b} *}$ & $19.9 \pm 3.5^{\mathrm{a}}$ & $11.2 \pm 1.7^{\mathrm{b} * *}$ & $16.7 \pm 3.5^{\mathrm{ab} * *}$ & $19.5 \pm 4.3^{\mathrm{a}^{\dagger}}$ & 0.003 \\
\hline Feeding & $12.7 \pm 1.0^{\mathrm{ab} *}$ & $12.7 \pm 2.7^{\mathrm{ab}}$ & $11.2 \pm 1.7^{\mathrm{b} * *}$ & $8.0 \pm 3.1^{\mathrm{b} * *}$ & $17.3 \pm 3.0^{\mathrm{a}}$ & 0.002 \\
\hline Grass eating & - & $5.2 \pm 1.6$ & - & $8.6 \pm 2.8^{* *}$ & - & $0.080^{1}$ \\
\hline Soil eating & - & $2.1 \pm 0.6$ & - & - & $2.2 \pm 1.2 * *$ & $0.838^{1}$ \\
\hline Exploring & $3.3 \pm 0.8^{\mathrm{c} \dagger}$ & $12.2 \pm 1.0^{\mathrm{ab}}$ & $9.2 \pm 4.1^{\mathrm{bc}}$ & $5.1 \pm 1.4^{\mathrm{c}^{\dagger}}$ & $16.2 \pm 5.2^{\mathrm{a}^{\dagger}}$ & $<0.001$ \\
\hline Resting & $74.3 \pm 4.0^{\mathrm{b} *}$ & $54.8 \pm 6.7^{\mathrm{a}}$ & $71.1 \pm 4.3^{b}$ & $70.4 \pm 9.6^{b}$ & $52.1 \pm 5.7^{\mathrm{a}^{\dagger}}$ & $<0.001$ \\
\hline Others & $9.8 \pm 3.2$ & $13.1 \pm 3.4$ & $8.5 \pm 1.0$ & $7.9 \pm 6.5$ & $12.2 \pm 3.5$ & - \\
\hline
\end{tabular}

IS, indoor housing system; OP, outdoor pasturing system; CF, concrete floor paddock system; FG, concrete floor paddock system with fresh grass; SF, soil floor paddock system; SD, standard deviation.

Values are expressed as mean \pm SD $(\%)$.

${ }^{1}$ The Student's $t$-test between OP vs FG or SF

a,b,c Means with different letters differ significantly in each behavior $(\mathrm{p}<0.05)$.

$\dagger, *, * *$ Means with symbols differ significantly from means in the prior period in each behavior $(\mathrm{p}<0.1,0.05,0.01)$. 
fattening stages from the prior to the latter periods.

Event behaviors: Frequencies of event behaviors are given in Table 4. Disturbed behavior was observed more frequently in IS pigs than in OP pigs (IS/OP = 33.6 and 11.9 in the prior and latter periods, respectively). IS pigs never expressed playing and rooting, whereas OP pigs performed both behaviors. Chewing behavior was observed infrequently in IS pigs and frequently in OP pigs (OP/IS = 12.4 and 76.6, respectively). There were no differences in the frequencies of the agonistic behavior and the affiliative behavior of IS and OP pigs. In OP pigs, the time spent chewing tended to increase and rooting tended to decrease from the prior to the latter periods $(\mathrm{p}<0.1)$, respectively, and there were no significant differences in the other behaviors between the prior and the latter periods. In IS pigs, no significant differences were observed in behaviors between the prior and the latter periods.

\section{Comparisons of CF, FG, and SF with IS and OP pigs}

Behavioral states: Behavioral states of pigs in the three treatments, CF, FG, and SF, are shown in Table 3. CF pigs showed no significant differences in state behaviors compared with IS pigs, and pigs in neither treatment expressed grass and soil eating in either the prior or the latter period. In the prior period, there were no differences between $\mathrm{CF}$ and $\mathrm{OP}$ pigs except that $\mathrm{CF}$ pigs did not express grass and soil eating. However, in the latter period, the time spent foraging was $44 \%$ lower and resting was $30 \%$ higher in CF pigs than in OP pigs.

FG pigs spent more time foraging and less time resting than IS pigs in the prior period, although no differences were observed between FG and IS pigs in the latter period. FG pigs never expressed soil eating but expressed more grass eating and foraging, and less resting than OP pigs in the prior period. In the latter period, FG pigs explored less and took more rest than OP pigs.

SF pigs spent longer foraging, eating soil and exploring, and less time resting than IS pigs in both periods. In addition, SF pigs never expressed grass eating but expressed more soil eating and exploring, and less resting than OP pigs in the prior period. The behaviors of SF pigs were the same as those of OP pigs in the latter period, except for grass eating.

Event behaviors: Event behaviors in the three treatments are shown in Table 4. The behaviors of CF pigs were the same as those of IS pigs, except for significantly lower frequencies of disturbed behavior only in the prior period. Differences in disturbed behavior disappeared in the latter period. The frequencies of chewing and rooting were lower in CF pigs than in OP pigs in both periods.

The expression of disturbed behavior was significantly lower and chewing was higher in FG pigs than in IS pigs in both periods. In addition, similar to IS pigs, FG pigs did not express playing and rooting, and also showed no agonistic behaviors in the latter period. FG pigs behaved in the same way as OP pigs, except that no rooting was exhibited in either period.

SF pigs expressed significantly fewer disturbed behaviors and more playing and rooting behaviors than IS pigs in both periods. There were no differences in event

Table 4. Frequencies of behavioral events in pigs in the five treatments

\begin{tabular}{|c|c|c|c|c|c|c|}
\hline \multirow{2}{*}{ Behavior } & \multicolumn{5}{|c|}{ Treatment $^{1}$} & \multirow{2}{*}{ p-value } \\
\hline & IS & OP & $\mathrm{CF}$ & FG & SF & \\
\hline \multicolumn{7}{|l|}{ Prior period } \\
\hline Disturbed behavior & $16.8 \pm 11.2^{\mathrm{a}}$ & $0.5 \pm 0.6^{\mathrm{b}}$ & $3.0 \pm 3.2^{\mathrm{b}}$ & $2.3 \pm 1.7^{\mathrm{b}}$ & $2.5 \pm 4.4^{\mathrm{b}}$ & 0.006 \\
\hline Playing & $0^{\mathrm{c}}$ & $4.5 \pm 1.3^{\mathrm{ab}}$ & $0.8 \pm 0.5^{\mathrm{bc}}$ & $1.0 \pm 1.4^{\mathrm{bc}}$ & $6.3 \pm 3.3^{\mathrm{a}}$ & $<0.001$ \\
\hline Chewing & $2.0 \pm 3.4^{\mathrm{c}}$ & $24.8 \pm 8.5^{\mathrm{ab}}$ & $6.3 \pm 5.4^{\mathrm{c}}$ & $29.8 \pm 9.1^{\mathrm{a}}$ & $11.3 \pm 2.9^{\mathrm{bc}}$ & $<0.001$ \\
\hline Rooting & $0^{\mathrm{b}}$ & $45.5 \pm 16.3^{\mathrm{a}}$ & $0.5 \pm 1.0^{\mathrm{b}}$ & $0^{\mathrm{b}}$ & $41.0 \pm 8.6^{\mathrm{a}}$ & $<0.001$ \\
\hline Agonistic behavior & $8.0 \pm 3.6$ & $3.5 \pm 1.7$ & $4.0 \pm 2.2$ & $6.3 \pm 3.2$ & $2.8 \pm 1.0$ & 0.053 \\
\hline Affiliative behavior & $3.8 \pm 2.1$ & $2.3 \pm 2.2$ & $3.5 \pm 2.9$ & $3.0 \pm 2.5$ & $3.8 \pm 1.7$ & 0.868 \\
\hline \multicolumn{7}{|l|}{ Latter period } \\
\hline Disturbed behavior & $15.5 \pm 11.0^{\mathrm{a}}$ & $1.3 \pm 1.5^{\mathrm{b}}$ & $7.5 \pm 5.2^{\mathrm{ab}}$ & $3.3 \pm 2.1^{\mathrm{b}}$ & $1.0 \pm 0.8^{\mathrm{b}}$ & 0.011 \\
\hline Playing & $0^{\mathrm{b}}$ & $1.3 \pm 1.9^{\mathrm{ab}}$ & $0 \mathrm{~b} * *$ & $0^{b}$ & $3.0 \pm 1.4^{\mathrm{a}}$ & 0.004 \\
\hline Chewing & $0.5 \pm 0.6^{\mathrm{b}}$ & $36.3 \pm 6.7^{\mathrm{a} * *}$ & $2.0 \pm 2.2^{\mathrm{b}}$ & $30.8 \pm 7.5^{\mathrm{a}}$ & $8.5 \pm 3.3^{b}$ & $<0.001$ \\
\hline Rooting & $0^{\mathrm{b}}$ & $26.0 \pm 11.2^{\mathrm{a} * *}$ & $0^{\mathrm{b}}$ & $0^{\mathrm{b}}$ & $51.0 \pm 6.8^{\mathrm{a}}$ & $<0.001$ \\
\hline Agonistic behavior & $3.3 \pm 1.7^{\mathrm{a}}$ & $3.0 \pm 1.2^{\mathrm{ab}}$ & $3.0 \pm 2.2^{\mathrm{ab}}$ & $0^{\mathrm{b} *}$ & $1.0 \pm 1.2^{\mathrm{ab} * *}$ & 0.018 \\
\hline Affiliative behavior & $2.0 \pm 0.8$ & $1.3 \pm 1.5$ & $1.3 \pm 1.3$ & $2.3 \pm 2.6$ & $3.5 \pm 0.6$ & 0.264 \\
\hline
\end{tabular}

IS, indoor housing system; OP, outdoor pasturing system; CF, concrete floor paddock system; FG, concrete floor paddock system with fresh grass; SF, soil floor paddock system; SD, standard deviation.

Values are expressed as mean $\pm \mathrm{SD}$ (Expression times/all observed times).

${ }^{1}$ The Student's $t$-test between OP vs FG or SF.

a,b,c Means with different letters differ significantly in each behavior $(\mathrm{p}<0.05)$.

$* *, *$ Means with symbols differ significantly from means in the prior period in each behavior $(\mathrm{p}<0.1,0.05)$. 
behaviors between SF and OP pigs in the prior periods; however, the frequency of chewing was around $25 \%$ less in SF pigs than OP pigs in the latter period.

\section{Behavioral differences between CF, FG, and SF pigs}

Behavioral states: A comparison of $\mathrm{CF}$ and $\mathrm{FG}$ pigs showed that grass eating was never observed in $\mathrm{CF}$ pigs and foraging was $48 \%$ lower than in FG pigs in the prior period; there were no differences in the latter period except for grass eating (Table 3). CF pigs never expressed soil eating and had significantly lower foraging and activity times than SF pigs in both periods. In addition, CF pigs showed a shorter duration of feeding and exploring in the latter period than in the prior period in comparison to SF pigs. Comparison of FG and SF pigs showed that FG pigs were not observed to eat soil, whereas SF pigs were not observed to eat grasses. Exploration time doubled and tripled in the $\mathrm{SF}$ pigs in the prior and the latter periods, respectively, compared to FG pigs. Moreover, SF pigs expressed more feeding and less resting than FG pigs in the latter period.

CF pigs spent a significantly lower amount of time foraging and feeding in the latter than in the prior period. The time spent foraging, feeding and eating grasses decreased in FG pigs in the latter period compared to the prior period. Additionally, the time spent exploring in FG pigs tended to decrease in the latter period. There was no difference in feeding between the prior and the latter periods in SF pigs, whereas other behaviours, such as foraging, soil eating and exploring tended to decrease or decreased significantly and resting tend to increase in the latter period.

Event behaviors: $\mathrm{CF}$ pigs expressed less chewing than FG pigs in both periods (Table 4). CF pigs played and rooted significantly less than SF pigs in both periods. FG pigs played less or not at all and chewed 2.6 and 3.6 times more than SF pigs in the prior and the latter periods, respectively.

In the latter period, $\mathrm{CF}$ and FG pigs ceased playing, and rooting. Agonistic behavior disappeared in FG pigs. SF pigs tended to decrease agonistic behavior in the latter period.

\section{Wounds on the body and performances}

The scores of wounds significantly differed between treatments (Table 5, $\mathrm{p}<0.001$ ). The highest score was in the IS pigs (47.5 \pm 22.7$)$, which was significantly higher than scores for pigs in the other treatments. The highest score in IS pigs was followed by CF (27\% of IS scores), FG (15\%), and OP (13\%) pigs, and the lowest average score found was for SF $(3 \%)$ pigs.

There were no significant differences in ADG $(\mathrm{kg} / \mathrm{d})$ between treatments in the prior period (Table 5). In the latter period, the ADG of OP and SF pigs was significantly higher than that of FG pigs.

In the prior period, the FCR in CF pigs was lower than FG and SF pigs. In the latter period, the FCR in SF pigs was lower than CF and FG pigs. The FCR in FG pigs was higher than other treatments in both periods.

\section{DISCUSSION}

\section{Comparison between IS and OP pigs}

There were no differences in expression of behavioral states between IS and OP pigs, except for grass eating and soil eating in the prior period. However, IS pigs reduced the time spent foraging and feeding in the latter period whereas OP didn't change. This is consistent with previous studies showing that pigs in a barren pen grew faster and spent less time eating per day (Bigelow and Houpt, 1988). In IS pigs, exploratory behavior also decreased and resting increased from the prior period to the latter period, which might be explained by habituation to a new and barren environment. This is supported by earlier work showing that modern, intensive systems cause chronic enervation and boredom in pigs (Wood-Gush and Beilharz, 1983; Wood-Gush and Vestergaard 1989). Less chewing and rooting and more disturbed behavior than OP pigs suggested that IS pigs had

Table 5. The scores of wounds on the body using the Welfare Quality assessment protocol (2009) and performances of pigs in the five treatments

\begin{tabular}{lcccccc}
\hline Treatment ${ }^{1}$ & IS & OP & CF & FG & SF & p-value \\
\hline Score of wounds on body & $47.5 \pm 22.7^{\mathrm{a}}$ & $6.25 \pm 4.6^{\mathrm{b}}$ & $13.0 \pm 4.2^{\mathrm{b}}$ & $7.0 \pm 2.7^{\mathrm{b}}$ & $1.5 \pm 2.4^{\mathrm{b}}$ & $<0.001$ \\
Prior period & & & & & \\
$\quad$ Average daily gain $(\mathrm{kg} / \mathrm{d})^{2}$ & $0.76 \pm 0.23$ & $0.68 \pm 0.18$ & $0.84 \pm 0.05$ & $0.53 \pm 0.13$ & $0.59 \pm 0.14$ & 0.082 \\
$\quad$ Feed conversion ratio & 3.43 & 3.16 & 3.10 & 4.10 & 3.65 & - \\
Latter period & & & & & \\
$\quad$ Average daily gain $(\mathrm{kg} / \mathrm{d})^{2}$ & $0.67 \pm 0.15^{\mathrm{ab}}$ & $0.91 \pm 0.09^{\mathrm{a} *}$ & $0.72 \pm 0.09^{\mathrm{ab} *}$ & $0.52 \pm 0.16^{\mathrm{b}}$ & $0.89 \pm 0.24^{\mathrm{a} *}$ & 0.016 \\
$\quad$ Feed conversion ratio & 3.78 & 3.56 & 3.80 & 4.72 & 3.33 & - \\
\hline
\end{tabular}

IS, indoor housing system; OP, outdoor pasturing system; CF, concrete floor paddock system; FG, concrete floor paddock system with fresh grass; SF, soil floor paddock system; SD, standard deviation; ADG, average daily gain.

${ }^{1}$ The Student's $t$-test between OP vs FG or SF.

${ }^{2}$ Values are expressed as mean $\pm \mathrm{SD}$.

${ }^{a, b}$ Means with different letters differ significantly in each line $(\mathrm{p}<0.05)$.

* Means with symbols differ significantly from means of ADG in the prior period $(\mathrm{p}<0.1)$. 
little opportunity to satisfy their motivation to express oral activities, such as foraging and exploring, which can lead to increased frustration in pigs. Pigs are thought to have a strong motivation for oral behavior (van Putten, 1979). This leads pigs to perform redirected oral behaviors to pen fittings (Petersen et al., 1995; Guy et al., 2002) and pen mates (Beattie et al., 1995; de Jong et al., 1998) when they have less opportunity to perform the normal oral activities. OP pigs expressed more chewing and less rooting in the latter period than in the prior period, whereas time spent foraging and exploring did not change between the two periods. These results suggest that OP pigs behaved consistently throughout their growing stage, which might lead to higher $\mathrm{ADG}$ in the latter period. In addition, play behavior as an expression of positive emotion was performed in OP pigs even in the latter period when the expression of play behavior is usually rarely observed.

There were no differences in social activities between IS and OP pigs. The IS treatment provided $1.2 \mathrm{~m}^{2} /$ head of floor space which satisfies the space requirements for pigs (Petherick, 1983; Spoolder et al., 2000). However, Anil et al. (2007) reported that injury scores increased with increasing stocking density. Jensen (1984) also reported that interactions between pigs, including biting, increased significantly at a lower space allowance. Space restriction causes chronic stress (Meunier-Salaun et al., 1987; Pearce and Peterson, 1993) and aggressive behaviors (Randolph et al., 1981) in pigs. Despite satisfying the space requirement in this study, the score of wounds on the body were significantly higher in IS pigs. This may be the result of severe redirected and abnormal behaviors to pen mates of IS pigs suffering from chronic stress such as thwarting of normal foraging, exploring, chewing, and rooting.

The above results, play behavior as the expression of positive emotion and lower stress, suggest that OP pigs may not only be free from distress and negative emotions but are also more comfortable, which may improve productivity.

\section{Characteristics of CF, FG, and SF pigs}

The behaviors of CF pigs were almost as same as that of IS pigs. Although many studies showed that reducing space allowance causes chronic stress and leads to disturbed behavior (Petherick, 1983; Pearce and Paterson, 1993), the effect of space allowance may not be long lasting. Compared with the behaviors of OP pigs, CF pigs showed less chewing and rooting in both periods and were less active and did not play in the latter period. Productivity in CF pigs was similar to that in IS pigs except the wound scores. The complexity of the environment may also be more important than space for improving animal welfare (Olsen, 2001).

Grass eating was particularly higher in FG pigs than in OP pigs in the prior period and was reduced by half in the latter period. It is probable that pigs perform this behavior only when stimulated by an adequate stimulus. The number of disturbed behaviors and wound scores in FG pigs were the same as that in OP pigs and was less than that in IS pigs, whereas chewing was the same as that in OP pigs and was more frequent than in IS pigs. However, FG pigs showed the lowest ADG in both periods. Although FG pigs spent much time expressing the consummatory behaviors of foraging such as chewing and grass eating, these behaviors might not contribute to ADG, which suggests that grasses have little nutritive value. In addition, the time spent feeding was significantly suppressed in FG pigs in the latter period. The high expression of grass eating is thought to satisfy the behavioural need of FG pigs, but not to improve productivity, which suggests that grass feeding is not suitable for improving pigs' welfare.

A soil floor stimulated not only rooting but also chewing as oral behavior for pigs. In addition, the softness of the soil floor might encourage pigs to play because of its lower impact on the feet and limbs (KilBride et al., 2009). Consequently, SF pigs could perform a wide array of their behavioral repertoire (Haskell et al., 1996). Behaviors and performances in SF pigs were similar to those in OP pigs. These results indicate that a soil floor might greatly contribute to improving the welfare of pigs.

\section{Differences among CF, FG, and SF pigs}

Foraging was expressed the least and resting the most in $\mathrm{CF}$ pigs. Exploratory behavior was occurred least and chewing most in FG pigs while playing was highest in SF pigs. Scores of wounds on the body decreased in treatment order from $\mathrm{CF}$, to $\mathrm{FG}$, to SF pigs, but these differences were not significant. In the latter period, before shipping, ADG was higher and FCR and wound scores were lower in SF pigs. SF pigs expressed much rooting and exploring as appetitive behaviors of foraging, which might stimulate the eating of the concentrate as a consummatory behavior, as explained by the motivational model proposed by Hughes and Duncan (1988). Stimulating foraging as a consummatory behavior in SF pigs might result in higher ADG and lower FCR than other treatments.

\section{CONCLUSION}

A pasture rearing system was better than an indoor system for pigs' welfare, as shown by the long term expression of normal oral behaviors which are strongly motivated and play behavior which is an indicator of positive emotion. In addition, OP pigs showed relatively few wounds on the body and favourable live weight gain. On the basis of these results, the study has confirmed that pasture rearing systems provide a persistent high welfare environment for pigs. The behaviors and performances of 
pigs in SF resembled those of pigs in the pasture. This led to the conclusion that the presence of a soil floor to stimulate appetitive feeding behavior and emotionally supportive play behavior, is the most important component of grazing system for improving the welfare of pigs.

\section{CONFLICT OF INTEREST}

We certify that there is no conflict of interest with any financial organization regarding the material discussed in the manuscript.

\section{ACKNOWLEDGMENTS}

This work was supported by the Ito Foundation. We gratefully acknowledge the farm staff at the Field Science Center and the laboratory staff in the Land Ecology and Animal Welfare, Graduate School of Agricultural Science, Tohoku University, for setting up our experiments and for discussion and helpful comments for this article. In addition, we thank Simon Turner for improving the English.

\section{REFERENCES}

Anil, L., S. S. Anil, and J. Deen. 2007. Effects of allometric space allowance and weight group composition on grower-finisher pigs. Can. J. Anim. Sci. 87:139-151.

Appleby, M. C. and D. G. M. Wood-Gush. 1988. Effect of earth as an additional stimulus on the behaviour of confined piglets. Behav. Processes 17:83-91.

Baxter, S. 1984. Intensive Pig Production: Environmental Management and Design. Granada Publishing Ltd, London, UK.

Beattie, V. E., N. Walker, and I. A. Sneddon. 1995. Effects of environmental enrichment on behaviour and productivity of growing pigs. Anim. Welf. 4:207-220.

Beattie, V. E., N. Walker, and I. A. Sneddon. 1998. Preference testing of substrates by growing pigs. Anim. Welf. 7:27-34.

Beattie, V. E. and N. E. O'Connell. 2002. Relationship between rooting behaviour and foraging in growing pigs. Anim. Welf. 11:295-303.

Bigelow, J. A. and T. R. Houpt. 1988. Feeding and drinking patterns in young pigs. Physiol. Behav. 43:99-109.

Bracke, M. B. M., J. J. Zonderland, P. Lenskens, W. G. P. Schouten, H. Vermmer, H. A. M. Spoolder, H. J. M. Hendriks, and H. Hopster. 2006. Formalised review of environmental enrichment for pigs in relation to political decision making. Appl. Anim. Behav. Sci. 98:165-182.

Day, J. E. L., H. A. M. Spoolder, A. Burfoot, H. L. Chamberlain, and S. A. Edwards. 2002. The separate and interactive effects of handling and environmental enrichment on the behaviour and welfare of growing pigs. Appl. Anim. Behav. Sci. 75:177192.

De Jong, I. C., E. D. Ekkel, J. A. Van de Burgwal, E. Lambooij, S. M. Korte, M. A. W. Ruis, J. M. Koolhaas, and H. J. Blokhuis. 1998. Effects of strawbedding on physiological responses to stressors and behaviour in growing pigs. Physiol. Behav.
64:303-310.

Guy, J. H., P. Rowlinson, J. P. Chadwick, and M. Ellis. 2002. Behaviour of two genotypes of growing-finishing pig in three different housing systems. Appl. Anim. Behav. Sci. 75:193-206.

Haskell, M., F. Wemelsfelder, M. T. Mendl, S. Calvert, and A. B. Lawrence. 1996. The effect of substrate-enriched and substrate-impoverished housing environment on the diversity of behaviour in pigs. Behaviour 133:741-761.

Hughes, B. O. and I. J. H. Duncan. 1988. The notion of ethological 'need', models of motivation and animal welfare. Anim. Behav. 36:1696-1707.

Jensen, P. 1984. Effects of confinement on social interaction patterns in dry sows. Appl. Anim. Behav. Sci. 12:93-101.

KilBride, A., C. Gillman, P. Ossent, and L. Green. 2009. Impact of flooring on the health and welfare of pigs. In Pract. 31:390-395.

Martin, P. and P. Bateson. 1986. Measuring Behaviour. Cambridge University Press, Cambridge, UK.

Meunier-Salaun, M. C., M. N. Vantrimponte, A. Raab, and R. Dantzer. 1987. Effect of floor area restriction upon performance, behavior and physiology of growing-finishing pigs. J. Anim. Sci. 64:1371-1377.

Olsen, A. W. 2001. Behaviour of growing pigs kept in pens with outdoor runs: I. Effect of access to roughage and shelter on oral activities. Livest. Prod. Sci. 69:255-264.

Pearce, G. P. and A. M. Paterson. 1993. The effect of space restriction and provision of toys during rearing on the behaviour, productivity and physiology of male pigs. Appl. Anim. Behav. Sci. 36:11-28.

Petersen, V., H. B. Simonsen, and L. G. Lawson. 1995. The effect of environmental stimulation on the development of behaviour in pigs. Appl. Anim. Behav. Sci. 45:215-224.

Petherick, J. C. 1983. A biological basis for the design of space in livestock housing. In: Farm Animal Housing and Welfare (Eds. S. H. Baxter, M. R. Baxter, and J. A. D. McCormack). Martinus Nijhoff, The Hague, The Netherlands. pp. 103-120.

R Development Core Team. 2013. R: A language and environment for statistical computing ver.3.0.2. R Foundation for Statistical Computing, Vienna, Austria. http:/www.R-project.org/ Accessed October 2, 2013

Randolph, J. H., G. L. Cromwell, T. S. Stahly, and D. D. Kratzer. 1981. Effects of group size and space allowance on performance and behavior of swine. J. Anim. Sci. 53:922-927.

Spoolder, H. A. M., S. A. Edwards, and S. Corning. 2000. Legislative methods for specifying stocking density and consequences for the welfare of finishing pigs. Livest. Prod. Sci. 64:167-173.

Stolba, A. and D. G. M. Wood-Gush. 1989. The behaviour of pigs in a semi-natural environment. Anim. Prod. 48:419-425.

Van Putten, G. 1979. Ever been close to a nosey pig? Appl. Anim. Ethol. 5:298.

Welfare Quality Consortium. 2009. Welfare Quality assessment protocol for pigs (sows and piglets, growing and finishing pigs). Welfare Quality Consortium, Lelystad, Netherlands.

Wood-Gush, D. G. M. and R. G. Beilharz. 1983. The enrichment of a bare environment for animals in confined conditions. Appl. Anim. Ethol. 10:209-217.

Wood-Gush, D. G. M. and K. Vestergaard. 1989. Exploratory behavior and the welfare of intensively kept animals. J. Agric. Ethics 2:161-169. 